\title{
Design and Application of Micro-video Course Recording in "General City Planning" Course
}

\author{
http://dx.doi.org/10.3991/ijet.v11i05.5687 \\ Kanhua $\mathrm{Yu}$ \\ Chang'an University, Xi'an, Shanxi, China
}

\begin{abstract}
-as information technology flourishes, use ratio of network and mobile terminal devices keeps rising. Microlecture as a new course resource and learning style jumps into people's vision. This paper introduces a microlecture platform which is applied to teach General City Planning. The platform includes the following functions: microlecture making device, classroom live broadcasting and real-time video recording device, microlecture question and answer device, microlecture labeling device and microlecture searching device etc. Based on fully expounding the research background, domestic and overseas situations, this paper analyzes design thought, overall structure and teaching advantage of the platform. The experimental study shows that the microlecture platform is quick and convenient to use. Therefore, it is the optimal platform for both teachers and students.
\end{abstract}

Index Terms-microlecture, General City Planning course, internet-based learning

\section{INTRODUCTION}

The term "microlecture" does not refer to micro-content developed for micro-teaching, but refers to actual teaching content which applies constructivism method and aims at online study or mobile study [1]. Microlecture owns integrated teaching design links, including course design, development, implementation and evaluation etc. As a novel teaching form, microlecture has been praised highly by experts, scholars and grassroots teachers in domestic and overseas educational circles in recent years. On the whole, with concise video contents, teachers may explain key and difficult points of courses in a concentrated, audio-visual and online manner so as to give play to teaching value of microlecture to the largest extent [2]. Such teaching form entirely breaks through tedious and laggard teaching defects of traditional teaching, erects a brandnew bridge between teachers and students by the video and greatly improves teaching efficiency and effect [3]. Teaching idea of microlecture originated from "oneminute course" of Prof. David Penrose from San Juan College in New Mexico in 2008. He recorded teaching difficulties into one-minute video, shared it on individual social website, guided students for independent study and gained good effects. Bouwmeester R A M et al. have studied the influence of online formative tests (OFTs) abundant in hyperlinks to microlectures on test scores. The experimental results show that students who adopted online formative tests connected to microlectures gain higher scores especially in highly aligned summative tests[4]. Educators tried to combine microlectures with flipped classroom. The experimental results indicate that the advantages of microlectures for such classrooms are explored, including how they can be used to help students become more responsible for their learning, and how they can be applied by teachers to provide differentiated instruction [5]. As microlectures continuously go deep and make progress in teaching, such modern education technology starts to appear in engineering course teaching. Liu Rui et al. explored the application of microlectures combined with "flipped classroom" idea in college architecture courses and designed a microlecture teaching mode based on pre-class task, intra-class typical task and afterclass expanded task [6]. Such teaching reform method is approved by students. Su Xiaobing et al. proposed "element" teaching form of microlectures in college architectural design course teaching and systematically discussed the application of microlecture teaching from theory and practice [7].

The above researches on development and application of microlecture informatization platform offer valuable experience for microlecture teaching research and also provide detailed reference for in-depth study in this paper. However, some researches also indicate microlecture teaching method still has some defects. 1. Relative to traditional $45 \mathrm{~min}$ teaching class example, "microlecture" can be called "class example fragment" or "micro-class example, but such teaching content is fragmented, and the knowledge is not continuous [8.9]. 2. In existing technology, the content of microlecture learning platform is single, and it is inconvenient to use, so a microlecture learning platform with richer contents and more convenient use is required to promote teachers and students to better impart and learn knowledge [10].

Based on the above background, this paper designs a microlecture learning platform suitable for General City Planning, verifies its benefits in practical teaching through teaching experiment and highlights feasibility and superiority of application of microlecture teaching mode in college architecture teaching. Hence, this paper lays a foundation for popularization and application of microlecture platform in teaching college architecture teaching.

Based on the above research background, this paper focuses on the following contents:

Firstly, a microlecture teaching platform based on mobile internet is designed. This platform based on information technology can visit via the browser or APP client and supports IOS, Andriod and Windows operating systems. Users can conduct online learning via tablet PC or PC terminal and breaks through the limitations of microlecture learning platform, such as single content and inconvenient use.

Secondly, the microlecture learning platform is microlecture study and social communication system. This sys- 


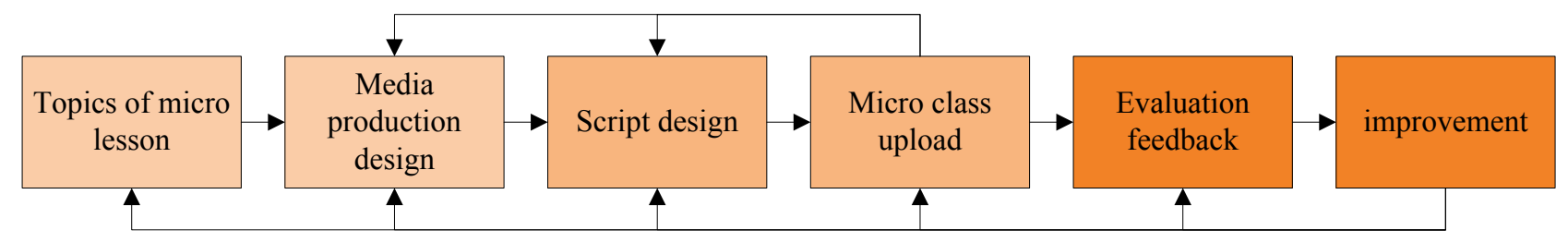

Figure 1. Framework structure of microlecture platform teaching design process

tem also includes concerned topic module, interest group module, microlecture retrieving module, microlecture issuing module and microlecture advertising module, further enriches microlecture teaching content and learning content and improves defects of microlecture teaching content such as fragmentization and non-systematicness.

\section{OVERVIEW OF GENERAL CITY PLANNING Microlecture PlatForm}

\section{A. Design thought}

The platform design is based on general process of traditional microlecture teaching, i.e. microlecture topic selection, making, uploading, learning guidance and evaluation feedback. On this basis, the techniques about computer informatization platform construction are integrated. Based on the above design thought, general process of General City Planning microlecture platform teaching design is concluded as show in figure 1.

As shown in the figure 1, the original intention of platform design lies in continuous evaluation and feedback of teaching effect through implementation of microlecture teaching so as to improve timeliness of microlecture platform teaching. In teaching implementation, microlecture material making naturally becomes the highlight. It is also an important medium of teaching. Based on the above process, with the help of computer information technology, the platform will integrate difficult, important and doubtful points of General City Planning, stores them in the database of the system, forms rich network teaching resource system and creates a "handheld learning platform" in mobile internet era.

\section{B. Overall structure}

In specific platform structure design, $\mathrm{B} / \mathrm{S}$ architecture is adopted. When system platform design is completed, users can visit the platform, acquire learning resources on the platform and carry out online learning just by installing APP client. Besides, to enrich teaching practicability of the platform, system design also adopts modularized structure system. The structure embodies the architecture form of 2 large modules and 8 small modules. Each module focuses on the content and feature of General City Planning to carry out functional design so that function and extensibility of the whole platform are fully manifested.

This platform integrates numerous informatization functions and can achieve numerous functions such as microlecture making, releasing, learning and sharing. For example, users can view microlecture video of General City Planning online in recording device and record simultaneously. In uploading and releasing device, users can save the recorded microlecture videos into mainstream video formats such as MOV, FLV and RMVB and upload them to the platform. Besides, through learning sharing module, users can share learning resources to individual social communication media, such as QQ Zone and WeChat circle of friends and share learning experience so as to achieve generalization of platform propagation effect.

\section{COMPARATIVE EXPERIMENT STUDY BASED ON Microlecture TEACHING PlatForm}

\section{A. Objects of teaching experiment}

The students from Class (1) and Class (2) in Grade 4 of architecture specialty were chosen as the objects, and each class includes 28 students. Students in the two classes have no significant statistical differences in terms of age, gender and academic scores $(\mathrm{P}<0.05)$. In specific implementation, Class (1) served as the control class, and Class (2) was set to the experimental class.

\section{B. Teaching design thought}

Urban Planning Design was chosen as the teaching content. The course includes 54 class hours in total, involving two teaching modules: theory and practice. In specific teaching design, "microlecture platform teaching method" was applied for experimental class. Urban Planning Design microlecture teaching platform served as the teaching carrier to organize "integrated theory and practice of microlecture platform". "Traditional classroom teaching method" was adopted for control class. After the course teaching was finished, teaching effect contrast was conducted through collecting such indexes as contrast, theoretical examination score and practical examination score of students in two classes.

\section{Teaching implementation method}

\section{(1) Teaching method of control class}

During teaching students in control class, the teacher adopted traditional "theory teaching method". In other words, multimedia presentation, question asking and answering between teacher and students, task assignment and correction feedback were mainly used for teaching [6].

\section{(2) Teaching method of experimental class}

During teaching students in experimental class, the teacher took microlecture platform as the medium to design "full-process teaching mode". Figure 2 shows implementation process diagram of such teaching mode.

As shown in the figure 2, implementation process of "full-process teaching mode" based on microlecture platform includes three links.

Firstly, course introduction link. This link is the initial stage of Urban Planning Design teaching, where the teacher regarded microlecture platform as the implementation carrier, guided students to install client APP and made students autonomously view course introduction through mobile client medium. The specific course introduction is conducted in the form of "microlecture navigation", including course nature, teaching objective, main content and examination requirement etc. Students could 
PAPER

Design and Application of Micro-VIDEO Course ReCORding IN “General City Planning” Course

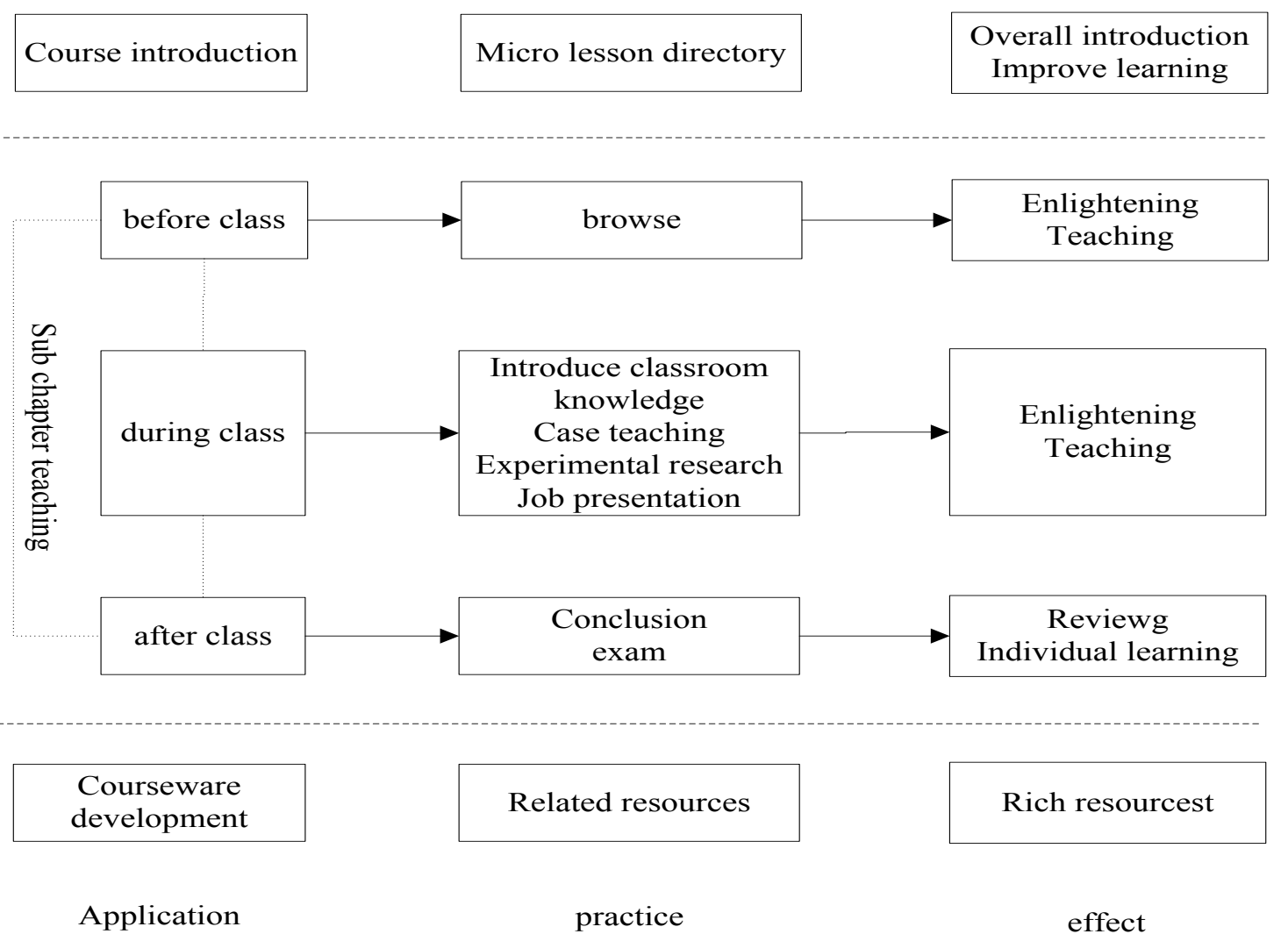

Figure 2. Implementation process diagram of "full-process teaching mode"

quickly know basic information of the course in a short time through independently viewing the navigation,or roughly know key and difficult points of this course according to their interest. In this way, classroom study in the later stage could become more targeted. Meanwhile, teacher's classroom introduction time could be saved, and the teaching efficiency could improve.

Secondly, teaching implementation link. This link covers pre-class, in-class and after-class parts, and each part has detailed implementation contents.

In pre-class part, the teacher uploaded the microlecture video to the teaching platform, and the contents mainly focused on key and difficult points of classroom teaching and highlighted the concise principle. As shown in Figure 3 and Figure 4, General Urban Layout Design in Urban Planning Design is taken for example. In video making, the introduction to three steps of general urban layout design was dominated, and students were guided to combine video for independent inquiry-based learning.

In in-class part, the teacher conducted targeted explanation according to students' pre-class microlecture learning conditions. The teaching process needs early design. The specific design template is as show in table 1 .

As shown in the table 1, the teacher displayed the teaching content in the form of level progress, which made classroom teaching pertinence and logic become stronger. In addition, in-classroom teaching also focused on microlecture platform. The teacher utilized multimedia network device to replay teaching video and answered students' questions in combination of video content.

In after-class part, the teacher may design hierarchical assignment system on microlecture platform according to students' classroom question answering. For example, for
TABLE I.

IN-CLASS MICROLECTURE TEACHING DESIGN TEMPLATE OF URBAN PLANNING DESIGN

Script design template for classroom teaching type micro lesson

Micro lesson chapter:
\begin{tabular}{|l|l|l|}
\hline Knowledge point description & & \\
\hline Classroomconception & & \\
\hline Teaching objectives & & \\
\hline teaching process & & Hours \\
\hline Classroomstructure & content of courses & \\
\hline Titles & Show the name of the micro lesson & \\
\hline Problemimport & & \\
\hline \multirow{3}{*}{ Class explanation } & chapte & \\
\cline { 2 - 4 } & chapte & \\
\cline { 2 - 4 } & chapte & \\
\hline over & & \\
\hline Teaching summary & & \\
\hline
\end{tabular}

the students failing to well grasp knowledge points, the teacher may arrange general theory assignments. For the active students in classroom, some practice assignments may be arranged to test their practical operation ability. Of course, in the above link, students' assignment submission should be completed through microlecture platform.

Thirdly, extracurricular expansion link. This link further embodies the effect of microlecture platform on online interaction and exchange of students and teachers. Teachers and students can communicate and answer questions online through social communication module, search module, Video on Demand (VOD) module and sharing module, while students can share their learning experience to individual social communication platform and achieve "seamless" and "immediate" extension of teaching effect. 
PAPER

Design and Application of Micro-VIDEO Course ReCORding IN “General City Planning” Course

The application of micro class in the course of town planning

$\gg$ Micro teaching mode $\quad$ C HOME Micro lesson video recording HELP EXIT $\mathbb{8}$

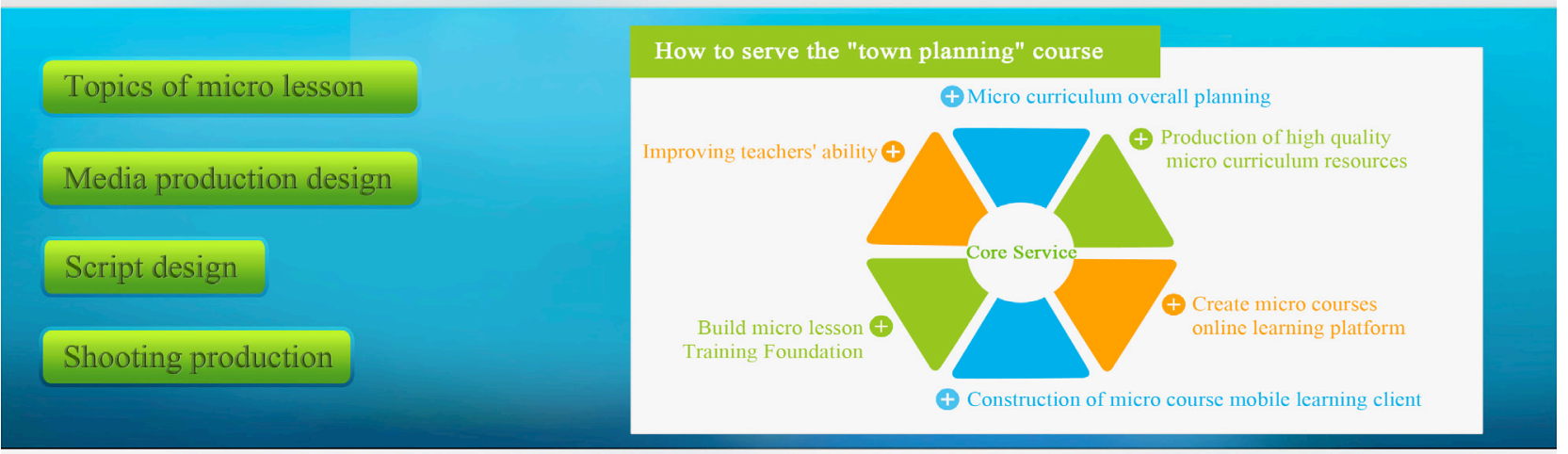

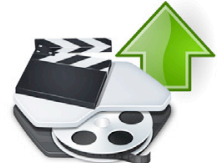

Micro class upload

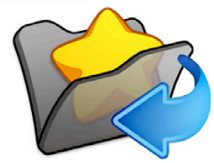

Evaluation feedback

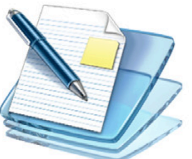

Improvement

More $\gg$

More »

More $\gg$

Figure 3. Microlecture platform content in pre-class guidance link

The application of micro class in the course of town planning

Application model

HOME Micro lesson video recording HELP EXIT \

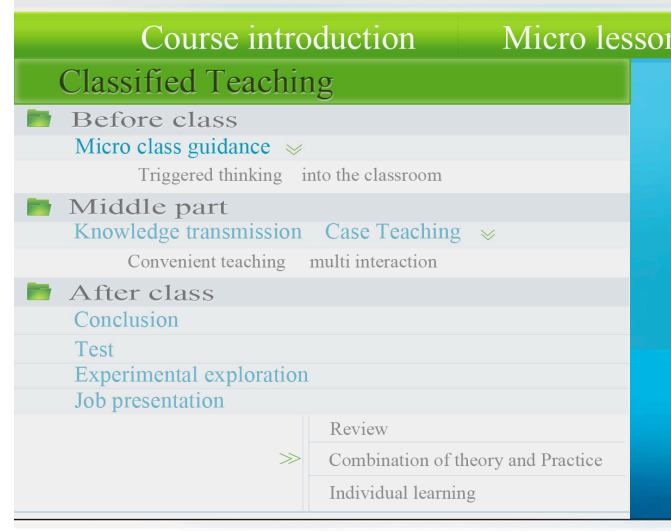

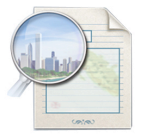

Courseware development

Application link »

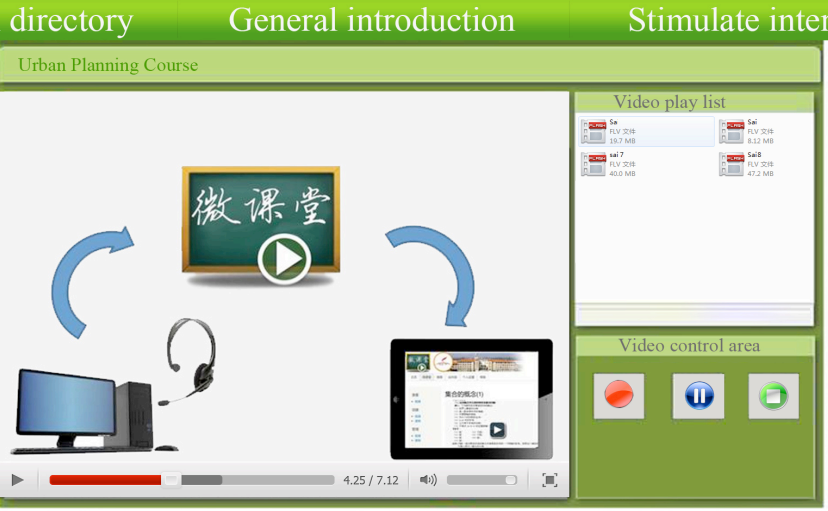

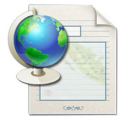

Related resources

Concrete form

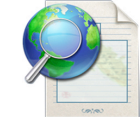

Expand resources

Figure 4. Microlecture platform content of General City Planning

\section{Contrastive analysis of teaching effect}

After teaching for 54 class hours, learning situations of students in the two classes were collected with questionnaire and examination score sorting. The specific statistical results are as in figure 5, figure 6 and figure 7.
As shown in Figure 5, microlecture platform teaching method can significantly improve students' learning interest (chi-square test, $\mathrm{P}<0.001$ ). Interested students in experimental group are $30 \%$ more than students in control group, while uninterested students in experimental group only account for $22 \%$ of students in control group. 
PAPER

Design and Application of Micro-Video Course Recording in “General City Planning” Course

As shown in Figure 6, microlecture platform teaching method can significantly improve students' theory examination scores (chi-square test, $\mathrm{P}<0.001$ ). The excellent and good levels in experimental group are 3 times and 1.7 times of those in control group. The middle and qualified scores in experimental group are lower than those in control group. $20 \%$ of students in control group flunk, while all students in experimental group pass the examination.

As shown in figure 7, microlecture platform teaching method can significantly improve students' practice examination scores (chi-square test, $\mathrm{P}<0.001$ ). Excellent rate and good rate in experimental group are $35 \%$ and $30 \%$,

\section{Experimental group}

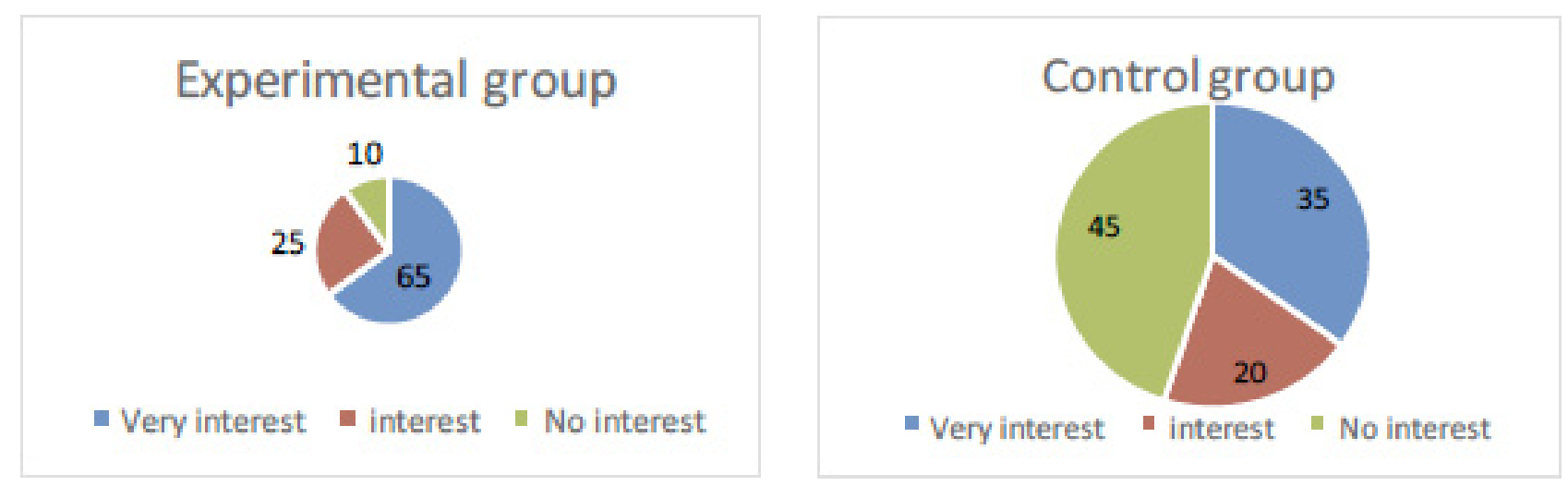

respectively, and the sum of the two reaches $65 \%$. The number of students failing in the exami^nation is 0 . Excellent rate and good rate in control group are $15 \%$ and $20 \%$, respectively, and the sum of the two is only $30 \%$. There is $10 \%$ failure rate in control group.

As shown in figure 5, figure 6 and figure 7 , the students in experimental group are significantly superior to students in control group in terms of learning inertest, theory examination scores and practice examination scores. It thus can be seen that compared with traditional teaching mode, teaching effect of microlecture platform teaching method is better.

Figure 5. Statistical table of students' learning interest (\%)

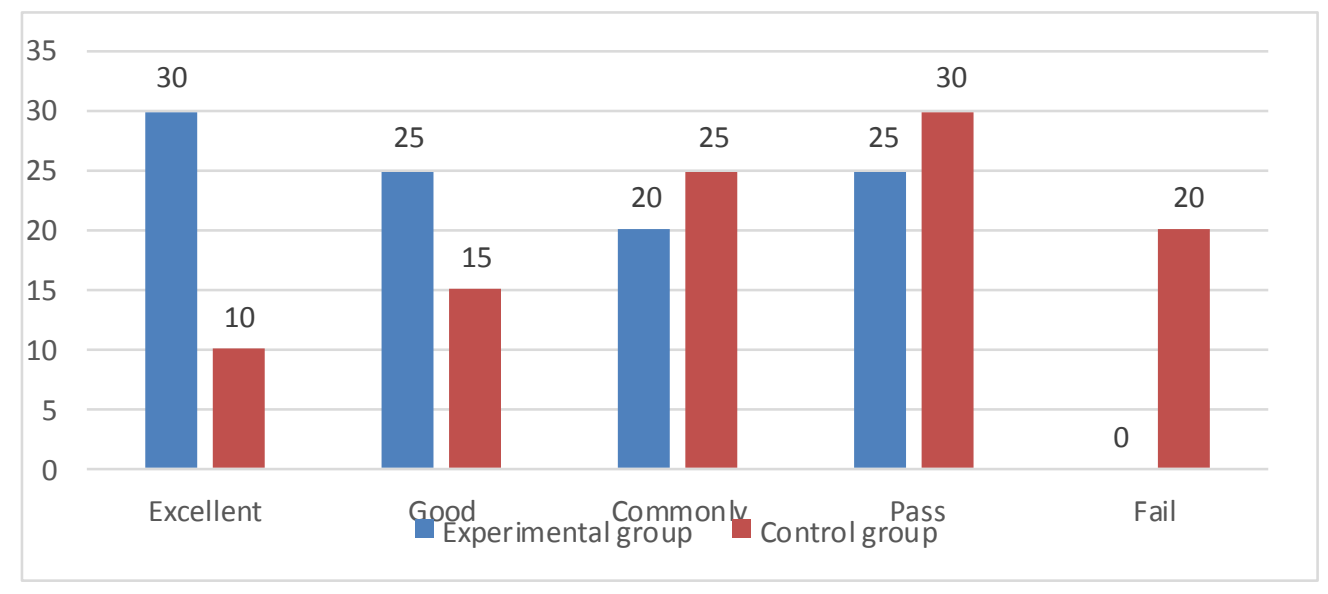

Figure 6. Statistical table of theory examination scores (\%)

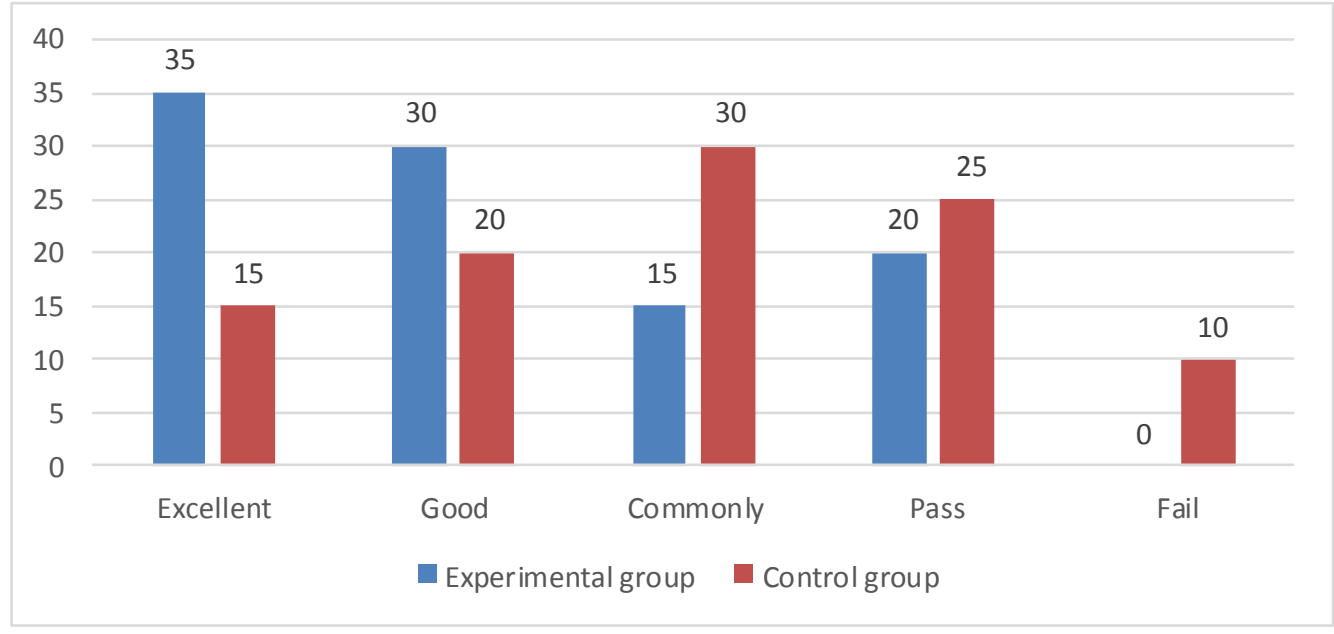

Figure 7.

Statistical table of practice examination scores (\%) 


\section{CONCLUSIONS}

Based on implementing teaching practice by taking microlecture platform as a teaching medium, this paper quantitatively compares learning attitude to Urban Planning Design, theory examination scores and practice examination scores of students in experimental class and control class and verifies the effectiveness of microlecture platform on Urban Planning Design teaching.

It is found from investigating improved microlecture platform teaching experiment that, firstly, it can improve students' learning interest. Most students in experimental class express that functional diversification, teaching entertainment and communication convenience of microlecture platform make them eye-opening and stimulate their learning interest invisibly. The reason may be that, in traditional classroom teaching, teachers impart a lot of knowledge to students mainly through systematic and meticulous explanation. Such teaching form is single, and the teaching method is rigid. Microlecture is a microcourse resource which is constructed and generated on the basis of knowledge points. In the process of microlecture mode design, the application of graph, image, PPT, flash and other diversified information technology methods can optimize classroom teaching resources and greatly enrich teaching organization pattern. Meanwhile, the design in this research further breaks through the limitations of microlecture learning platform, such as single content and inconvenient use, and improves learning interest. Secondly, it can boost students' academic scores. By contrasting theory examination scores and practice examination scores in this experiment, excellent rate in experimental class improves significantly. More than $80 \%$ of students in experimental class well approve microlecture platform teaching form and express that microlecture teaching becomes the major driving force of them to increase examination scores. This is because that microlecture pattern is based on video teaching. Under the support of network information technology, microlecture pattern can integrate teaching resources about the teaching theme, create a theme-based and structured resource unit environment through organizing and presenting comprehensive teaching resources and forms a teaching resource organization mode with small capacity and multiple resources. Microlecture platform pays more attention to integrated course design and teaching organization, further enriches teaching content and learning content of microlecture and improves defects of microlecture teaching content such as fragmentization and non-systematicness. Such advanced teaching method and optimized teaching mode can promote teaching effect and students' examination scores.
In conclusion, the application of microlecture platform in Urban Planning Design can achieve online, seamless, dual-communication and multifunctional course teaching by computer informatization. Microlecture platform greatly facilitates improvement of students' learning interest and examination scores. For traditional teaching, this platform can well supplement and extend teaching. Therefore, this platform deserves further popularization and application in other courses of college architecture specialty.

\section{REFERENCES}

[1] Zhang L.Y., "Experiment on Microlecture Scientific Research Project to Promote the Rapid Development of the Master Teacher Candidate," Journal of Fujian Institute of Education, no. 5, pp. 9, May 2012.

[2] Morris L.V., "Little lectures?," Innovative Higher Education, vol. 34, no. 2, pp. 67-68, April 2009. http://dx.doi.org/10.1007/s107 55-009-9108-1

[3] Liu X., Wang L., "The analysis on systematic development of college microlecture," Higher Education Studies, vol. 3, no. 6, pp. 65, June 2013. http://dx.doi.org/10.5539/hes.v3n6p65

[4] Bouwmeester R.A.M., De Kleijn R.A.M., Freriksen A.W.M., Van Emst M.G., Veeneklaas R.J., Van Hoeij M.J., et al., "Online formative tests linked to microlectures improving academic achievement," Medical teacher, vol. 35, no. 12, pp. 1044-1046, August 2013. http://dx.doi.org/10.3109/0142159X.2013.818633

[5] Sweet D., "Microlectures in a flipped classroom: Application, creation and resources," Mid-Western Educational Researcher, vol. 26, no. 1, pp. 52-59, January 2014.

[6] Liu R., Wang H.Y., "Design and Practice of "Flipped Classroom" Teaching Mode Based on Microlecture," Modern Educational Technology, no. 5, pp. 65-68, May 2014.

[7] Su X.B., Guan J.Q., Qian D.M., Zhu Z.T., "Analysis of Microlecture Concept and Study on Its Teaching Application," China Educational Technology, no. 7, pp. 35-37, July 2014.

[8] Clair R.S., "Rimbaud et la Commune. Microlectures et perspectives (review)," Nineteenth-Century French Studies, vol. 41, no. 1, pp. 181-184, January 2012. http://dx.doi.org/10.1353/ncf.2012. $\underline{0040}$

[9] Liang L.M., Cao Q.Q., Zhang B.H., "Research on a Micro-lecture Design Model through Comparative Case Study," Open Education Research, no. 1, pp. 65-73, January 2013.

[10] Yang H.Y., "How Can Micro Courses Attract Learners: Ponderings for Video Recordings of China's 1st Colleges' Micro Courses Competition," China Educational Technology \& Equipment, vol. 24, no 12, pp. 20, December 2013.

\section{AUTHORS}

Kanhua YU is an Associate profession of School of Architecture, Chang'an University, Xi'an 710061, Shanxi, China. His research interests include City Planning and Micro-video Course. (yukanhua@yeah.net)

Submitted 29 March 2016. Published as resubmitted by the author 03 May 2016. 